\section{(6) OPEN ACCESS}

\title{
An activist's argument that participant values should guide risk-benefit ratio calculations in HIV cure research
}

\author{
David Evans
}

\section{Correspondence to}

Dr David Evans, 705 El Centro Street, South Pasadena, CA 91030, USA; devans@projectinform.org

Received 29 January 2016 Revised 1 December 2016 Accepted 2 December 2016 Published Online First 6 January 2017

\begin{abstract}
The patient empowerment movement, spurred by AIDS activism in the 1980s, quickly evolved to encompass how study participants are considered and treated in clinical research. Initially, people fearing death of AIDS sought early access to experimental medications that had not undergone rigorous testing in hopes of extending their lives. Thirty years on, scientists are asking a different set of ethical questions about clinical research, this time in the pursuit of either a sterilising cure or long-term remission for HIV. Instead of hastening access to experimental drugs for the sickest, researchers are now testing interventions for eradicating or controlling the virus in typically very healthy HIVpositive individuals who have the most to lose from such interventions if something goes wrong. While clinical researchers and ethicists debate the merits and limits of this type of research they should avoid discounting altruistic motivations as a powerful factor in a prospective study participant's decisions to assume risks. My conversations with four men who participated in HIV cure studies confirmed the capacity of these people to make carefully considered decisions about risks and the sometimes substantial influence/sway of non-clinical benefits that may come from participation in cure-oriented research. Studies must undergo ethical and clinical review before proceeding, and not all participants of such studies will be able to weigh or understand risks and benefits as those profiled here. But respecting the self-agency of people living with HIV should be a goal in the design and conduct of cure research.
\end{abstract}

In 1983, a small group of people living with HIV gathered in Denver, Colorado, USA to discuss how horribly they (and others living with the disease) had been treated by a range of individuals and institutions, including healthcare providers. They wanted to respond in a forceful way and one of the defining outcomes of the gathering was a manifesto, now known as the 'Denver Principles', that stated, in part, "We condemn attempts to label us as 'victims,' a term which implies defeat, and we are only occasionally 'patients,' a term which implies passivity, helplessness, and dependence upon the care of others. We are 'People with AIDS." "1

A medical self-empowerment movement that grew out of feminism from the 1970s onwards took shape subsequent to the publication of this manifesto, and it has since revolutionised the practice of medicine globally. ${ }^{2}$ Beyond its application to direct medical care, it now also informs the design and conduct of clinical research. ${ }^{3}{ }^{4}$ As an activist for the past 24 years, I have advocated alongside of people living with HIV to ensure that science represents their best interests and amply respects their ability to make informed decisions, both as advisors on research design and implementation and as study participants.

One of the concepts upon which people living with HIV have insisted since the 1980s is the right to assume risks in the pursuit of effective treatments-risks that the research establishment has sometimes deemed too great. Initially, exposure to those risks was confined to individuals who were in danger of immediate death and who fought for access to unapproved drugs, many of which were illegally imported into the USA. ${ }^{5}$

More recently, however, scientists have begun aiming for a much more ambitious goal: to cure HIV disease, or to at least place it into long-term remission without the need for antiretroviral therapy (ART)-what in common parlance has come to be called 'cure research'. ${ }^{6}$ As the earliest proof-of-concept studies have gotten underway, the AIDS research paradigm has been turned on its head. Rather than exposing the sickest to experimental drugs or procedures, it is instead the healthiest who are deemed an ideal population for study, because the likelihood of provoking the desired effect on the virus is greater. Those more recently infected have the most to lose, as their reservoir of latent HIV is much smaller, but that also potentially makes them better candidates for a cure intervention should one ultimately be found. ${ }^{78}$

What's more, it is highly unlikely that there will be health benefits to those who would participate in such studies. In fact, studies that would include an interruption of ART run counter to current US treatment guidelines. ${ }^{9}$ While this is true of many studies-after all, research is not meant primarily to be therapeutic-the efficacy and safety of ART sets a substantially high bar for a new cure strategy to overcome. If we are successful in communicating this to prospective study participants, we must think about and respect their motivations, and specifically their altruistic motivations.

George Annas argues in this issue that even raising the general prospect of an HIV cure at this 
early stage could have quite troubling consequences, for society in general, but particularly for those deciding whether to participate in a study ${ }^{10}$ Obviously, language is critical to consent and decision-making, and words such as 'cure' and 'remission' are loaded. But there is a difference between someone mistakenly believing they might be cured or have their health improved if they enrol in a trial and someone deriving great psychological benefit from the notion that their participation may one day benefit others.

Researchers and ethicists (as well as community members, who often serve on study review boards) must protect study participants from unethical treatment and serious harm. This includes instituting effective and up-to-date procedures for informing study participants about risks and benefits, assessing understanding, and promoting effective decision-making. A guiding principle in this effort, however, should be that of protection, which can become overly paternalistic, and of respect for participants' capacity to judge risks and benefits based on their own values. For some patients, study participation has the potential for transforming the adverse experience of being diagnosed with HIV into a meaningful event that allows them to materially help others like themselves.

It is critical, of course, to remember that some might be less equipped to fully understand the risks posed by a particular research study, or have unrealistic expectations of medical benefit. Researchers and ethicists should remain wary about the prospect of therapeutic misconception, defined by Appelbaum and colleagues as 'when research subjects fail to appreciate the distinction between the imperatives of clinical research and ordinary treatment'. ${ }^{11}$ With cure research, there is also the danger of participants having a much more optimistic assessment of the potential for benefit than is likely, even when they understand that the primary purpose of the study is experimental and not therapeutic. Research standards and ethics must take this into account. But it is equally true that they might not be able to articulate for themselves or others the benefits that they believe will accrue to them through their participation in a study.

Researchers and ethicists should also avoid unnecessary paternalism and include people living with HIV in setting guidelines for this new type of research. They should calculate how best to assess and balance risks and benefits in partnership with them. It is important to characterise what has been judged to be ethical, and with whom and how this judgement was made.

\section{WEIGHING RISKS AND BENEFITS: SEVERAL PERSPECTIVES}

As a long-time AIDS activist and healthcare journalist I have become intimately familiar with how scores of people living with HIV, whom I have spoken to, feel about research. I have also served as a representative of their needs by providing input on study designs, editing informed consent documents and serving on institutional review boards. Over the years I have witnessed the evolution of how people living with HIV approach clinical research and how their input is viewed by professionals. This experience, especially as it relates more recently to HIV cure research, has led to the formation of working assumptions about how some people with HIV view cure study participation and the value that they place upon it.

In an informal canvas of four HIV-positive men about what participation in HIV cure research had meant to them, ${ }^{i}$ two general themes emerged: First, that the men were highly concerned with and curious about the risks of the studies in which they were asked to participate; and second, that despite knowing in advance of participation that there was very little chance that they would be cured or helped medically, they derived significant benefit from the conviction that being in the study would help others like themselves.

Though these conversations fall short of the formal rigour employed by researchers, and though a more scientific approach may contradict this analysis, they do reveal perspectives that are worthy of further exploration and demonstrate the value of involving people living with or affected by diseases in the framing of a hypothesis and a research plan to investigate it. A later paper may report different findings, and by the strength of its methods be given greater weight, but one may fairly argue that further exploration of this area would have value to the field.

Though formal study is the most acceptable means to confirm a hypothesis, it is possible to use anecdotes and personal experience to demonstrate a point and to build propositions ripe for further exploration. Thus do hypotheses often develop-from a 'hunch' to informal literature review or canvassing of stakeholders to a more formalised research process.

While two were comfortable sharing their first names, the other two asked that their names and personally identifiable information be withheld. To achieve this, pseudonyms will be used for the two who asked not to be named and certain key details, such as the institution where their studies took place, will be omitted.

Two of the men shared anecdotes about their personal participation in interventional studies of candidate cure interventions. The first person, Matt, participated in a trial of a gene therapy developed to modify his own CD4+ cells to make them resistant to HIV infection. The second, Gary, had received an allogeneic stem cell transplant to treat myelodysplastic syndrome from previous cancer treatments. To understand if the transplant procedure might have eliminated HIV sufficiently to keep the disease at bay, the study required him to interrupt his antiretroviral regimen. The outcomes of both of these studies are in the literature. $^{1213}$

The other two individuals, who will be called Thomas and Dominic, shared how they came to enter and feel about studies that collected blood and tissue for analysis of the viral reservoir. Thomas and Dominic were diagnosed very early following HIV infection and had also been approached about or considered participation in a study that would involve interruption of ART to test cure concepts, something not generally recommended by the US antiretroviral treatment guidelines ${ }^{9}$ and that carries health risks.

\section{MAKING DECISIONS ABOUT THE RISKS OF CURE RESEARCH}

Matt, from the gene therapy study, recounted that he purposefully sought out participation in the trial after consulting with

${ }^{\mathrm{i}}$ Interviewees were told that the author was soliciting input from HIV-positive individuals about their participation in and views about HIV cure-oriented research for the purposes of an opinion article in the Journal of Medical Ethics. Interviewees were told that they may remain completely anonymous (eg, elimination of any identifying information) or share their names and the studies they participated in. An ethicist who is an expert in ethical review for human trials was consulted and deemed that institutional review board approval was not necessary as the interviews were not formally research. 
activists and researchers familiar with cure research. He stated that he never believed that the intervention, which was designed as a proof-of-concept study, would cure him, though he did hope for another beneficial outcome that had been noted in previous research, namely that his CD4+ cell count might increase and be sustained for a time. Though some might consider this therapeutic misconception, previous data indicated that a CD4+ count increase was plausible and might be sustained. Matt knew this might confer no clinical benefit, but decided to participate anyway.

He explained that he was highly informed about and comfortable with the potential risks involved, and that he'd done his own research prior to enrolling. The risks included rare events associated with the collection of his cells, blood and tissue, as well as treatment and reinfusion of cells. He also understood the more serious but theoretical risk of malignancies and other downstream effects of gene modification.

He indicated that his consultation of experts in the field all led to the same conclusion about the potential for cancer or other off-target gene mutations. "Everybody I asked [about this] said the same thing, [with] all of the preclinical animal information," he said. "[I] talked to a lot of researchers and activists," who told him that mutagenesis had not been seen in mammals.

While it is theoretically possible that he may have minimised the risks to himself out of a subconscious desire to be cured, conversations I had with him while he was in the study in 2010 indicated that he was very clear-eyed about his decision.

Carefully researching the potential risks of study involvement, and vetting information provided by a study's investigator, was a trend echoed by two other participants.

Gary, the transplant recipient, also took great pains to understand the risks involved in the study in which he participated. The principal investigator of the study, Timothy Heinrich, recounted that Gary had sent extensive comments and questions about the informed consent and that they had several conversations before Gary consented to participate.

Thomas, one of the other men I spoke to, was confronted with the option of immediately going on ART upon diagnosis as is standard of care, and later, thanks to the study, with the choice to interrupt therapy, both of which he said required careful consideration, online research on his own and lengthy conversations with his own clinician. While he was eager to play a helpful role in the research process, he also knew he had limits and he wanted to understand the details of the study well enough to decide whether it would exceed those limits.

In each of these cases, the men carefully considered the risks and took pains to understand them. This type of personal empowerment and self-education in the research process is exactly what thousands of people living with HIV have demonstrated within both their healthcare and research participation going back 30 years. Something of note, however, is the lack of any formal assessment of understanding among the men about the studies for which they had volunteered, other than the verbal consenting process with study staff that was described to me.

\section{FINDING MEANING AND PURPOSE IN PARTICIPATION}

Aside from how they weighed the risks involved in the cure studies they enrolled in, all four men recounted the value they received from participating in those studies. Each said they had been guided by a desire to help others like themselves, to contribute to a world that has a cure for HIV in it. While a general sense of satisfaction from altruistic intent may not be a sufficient counterbalance to the kinds of risks involved in some cure studies, it is important that we do not overlook a more profound and tangible benefit that some report to have acquired as a result of study participation.

One of the men, Dominic, who was treated early and later participated in two studies, spoke of how the possibility that his contribution would benefit others actually transformed his grief about becoming infected.

It was so devastating when this happened to me, he said. But now I think there's a reason. I'm supposed to do these studies.

In a sense it's kind of a blessing, he also said. I figure if I'm going to have this then I'm going to do whatever I can to help someone, the next generation or the one after that. It would make something good out of something bad.

Gary ultimately derived similar emotional solace from his study participation, though his situation was rather unique and dramatic. In his case, he'd been sought out, because he was among a rare number of individuals who had remained on ART during his stem cell transplantation and whose cancer remained in remission (most other similar HIV-positive transplant recipients had died from recurrent cancer). As a consequence, the new donor cells would likely have been exposed to very little HIV and there was a possibility that the combination of stem cell transplantation and ART could have beneficially altered the dynamics of his infection. The only way to know for sure, however, was to take him off of treatment and see whether the virus-which could not be found using the most sensitive assays-would come back.

"The chances of me dying or having my health compromised sooner or more deeply came into my analysis and in deep conversations with my sister," he said. "But then I said 'Let's do this'. I felt I could help the HIV community, the medical research community, and hopefully myself. Hopefulness, in its many directions, was part of my decision."

Gary eventually had to contend with some negative consequences of that decision. After he went off of treatment his virus didn't come back, and this persisted week after week. Given that the only other person in whom this had happened was in fact cured, he found it impossible not to hope.

I'd wake up and think 'I'm not taking my pills and I may never take them again. I may be cured.' It was surreal, he said.

After 32 weeks, however, the virus did return and at first he felt quite devastated and still describes the experience as traumatic. Something the investigator in the study told him, however, caused a marked change in his emotional well-being.

Gary said, "Tim [the investigator] told me, and I'm paraphrasing, 'What you have done has given so much information and insight to the medical research cure community, Information that we never had before...[it] is changing and adding new directions to research."”

That felt so wonderful and warming, Gary said. It helped me emotionally compensate for [the negative part of the experience]. I felt that for me personally, I've added to the body of knowledge in a way that was unique and that only I could do. I offered myself as a testing lab, and though the research didn't identify a cure, I still feel really good about my participation, risks and all.

Gary's experience does mean that researchers must pay particular concern to the possibility of therapeutic misconception arising and growing over time if a study participant achieves sustained reductions in HIV below a certain threshold for days, weeks or months. It is easy to understand how a person living with HIV, who has a persistently low viral level, might begin to believe that it will never go back up. 


\section{THE CHALLENGE OF IDENTIFYING AND WEIGHING ALTRUISTIC MOTIVATION}

The thoughts and experiences recounted here are hardly universal to all people living with HIV. In fact, these men may be outliers. Certainly, not all people come into a study equally able to understand the potential risks and to balance them against the possibility of benefits that are most important to them.

This strengthens the imperative to use the most rigorous and innovative tools and processes to assess understanding and ensure adequate consent among HIV cure study participants. Given the potency of the prospect of a cure for people living with HIV, efforts to uncover the potential for therapeutic misconception are paramount. Gary's experience adds an important twist to this challenge. For him, a sliver of hope about having been cured grew to a strong belief that he had been. When the virus returned, he experienced emotional and psychological distress.

For early cure research, where there are few clinical rewards likely and where interventions may be worse than the standard of care, a lack of understanding of the research could cause great harm to the individual. They could also harm society if unexpected harms cause a path of exploration to come to a halt. Some non-cure HIV studies have shown a troubling lack of understanding and recall of the studies' aims and procedures by participants. ${ }^{1-16}$

Moreover, an editorial in The Lancet HIV called for studies of combinations of cure interventions, rather than testing single compounds sequentially before they may be combined. ${ }^{17}$ This is because cellular models have shown significant synergy in combinations that, used separately, had minimal effects. Such studies may increase risks, and they may make the risks more difficult for a prospective participant to understand.

Nevertheless, while these concerns are legitimate, they should not trump the great personal and societal need to find a cure for HIV. Current treatment is amazingly effective and safe, but it must be taken lifelong and we do not yet know what the very long-term effects might be. For the individual, stigma remains a relentless cause of psychological stress, which a cure may ameliorate. Moreover, in real world situations, we substantially fail to retain people with HIV in care and to achieve viral suppression. Current estimates by the Centers for Disease Control and Prevention suggest that fewer than a third of HIV-infected individuals in the USA are benefiting fully from ART, leaving them vulnerable to illness and death, and at risk of transmitting HIV to others and continuing the persistence of the epidemic. ${ }^{18}$ Lastly, lifelong treatment for the millions infected globally is simply not financially supportable. Though not articulated this explicitly, the four men I spoke to expressed a deep and personal awareness of the magnitude of HIV's negative impact on humanity and a sincere desire to help.

One way to manage the ethical concerns involved here is to follow a set of recommendations published in 2011 by UN AIDS and AVAC for good participatory practices. ${ }^{19}$ Though developed for HIV prevention trials, they can easily be adapted for cure research, and highlight the value of soliciting the input of people living with HIV and their advocates throughout the research process, from design to execution to dissemination of results. Such practices will ensure that when guidelines and review committees weigh the merits of a type of study design or a specific study, they consider the risks and benefits from the participant's point of view and can explain them adequately to those they wish to recruit. The cultural, experiential and linguistic expertise of community representatives, combined with the knowledge of social scientists, ethicists and researchers about how to minimise harms and support ethical studies quite simply makes for better studies.

\section{CONCLUSION}

As was called for by a courageous group of men facing one of the most terrifying illnesses in modern memory, we must not see people with HIV who would participate in cure studies as passive, helpless potential victims. Rather, we should recognise their great capacity to understand the risks they may confront as research participants and, after a careful ethical and scientific review, respect the motivations of those who decide that the benefits of knowing that their contributions may help others outweighs the risks.

Ultimately, we should not forget that a partnership between researchers and people living with HIV has contributed to the great progress we've made in treating HIV. There remain many scientific questions that must be answered to point the way to a safe and scalable cure, but they will not be answered if we stand in the way of the people who have decided to put their own well-being on the line so that others may one day benefit from their noble generosity.

\section{Competing interests None declared.}

Provenance and peer review Commissioned; externally peer reviewed.

Open Access This is an Open Access article distributed in accordance with the Creative Commons Attribution Non Commercial (CC BY-NC 4.0) license, which permits others to distribute, remix, adapt, build upon this work non-commercially, and license their derivative works on different terms, provided the original work is properly cited and the use is non-commercial. See: http://creativecommons.org/ licenses/by-nc/4.0/

\section{REFERENCES}

1 The Denver Principles. https://www.nlm.nih.gov/exhibition/survivingandthriving/ education/documents/OB2216-DenverPrinciples.pdf (accessed 2 Oct 2015).

2 Roberts KJ. Patient empowerment in the United States: a critical commentary. Health Expect 1999;2:82-92.

3 History of the ACTG. https://actgnetwork.org/History (accessed 2 Oct 2015)

4 History of CAB. http://idc.uc.edu/cabhistory.php (accessed 30 Sep 2015).

5 Kwitny J. Acceptable risks. New York: Poseidon Press, 1992:466.

6 Passaes CP, Sáez-Cirión A. HIV cure research: advances and prospects. Virology 2014;454-455:340-52

7 Chéret A, Bacchus-Souffan C, Avettand-Fenoël V, et al., OPTIPRIM ANRS-147 Study Group. Combined ART started during acute HIV infection protects central memory CD4+ T cells and can induce remission. J Antimicrob Chemother 2015;70:2108-20.

8 Krebs SJ, Ananworanich J. Immune activation during acute HIV infection and the impact of early antiretroviral therapy. Curr Opin HIV AIDS 2016;11: $163-72$.

9 Guidelines for the Use of Antiretroviral Agents in HIV-1 Infected Adults and Adolescents. https://aidsinfo.nih.gov/contentfiles/lvguidelines/adultandadolescentgl. pdf (accessed 5 May 2016).

10 Annas G. Cure research and consent: the Mississippi baby, Barney Clark, baby FAE and martin Delaney. J Med Ethics 2016;doi:10.1136/medethics-2015-103121.

11 Appelbaum PS, Roth LH, Lidz C. The therapeutic misconception: informed consent in psychiatric research. Int J Law Psychiatry 1982;5:319-29.

12 Tebas P, Stein D, Tang WW, et al. Gene editing of CCR5 in autologous CD4 T cells of persons infected with HIV. N Engl J Med 2014;370:901-10.

13 Henrich TJ, Hanhauser E, Marty FM, et al. Antiretroviral-free HIV-1 remission and viral rebound after allogeneic stem cell transplantation: report of 2 cases. Ann Intern Med 2014;161:319-27.

14 Flory J, Emanuel E. Interventions to improve research participants' understanding in informed consent for research: a systematic review. JAMA 2004;292: 1593-601.

15 Bergler JH, Pennington AC, Metcalfe M, et al. Informed consent: how much does the patient understand? Clin Pharmacol Ther 1980;27:435-40.

16 Sanchini V, Reni $M$, Calori $G$, et al. Informed consent as an ethical requirement in clinical trials: an old, but still unresolved issue. An observational study to evaluate patient's informed consent comprehension. J Med Ethics 2014;40:269-75.

17 Ananworanich J, Barré-Sinoussi F. Is it time to abandon single intervention cure trials? Lancet HIV 2015;2:e410-11.

18 Understanding the HIV Care Continuum. http://www.cdc.gov/hiv/pdf/dhap_ continuum.pdf (accessed 2 Oct 2015).

19 Good Participatory Practice: Guidelines for Biomedical HIV Prevention Trials 2011. http://www.avac.org/sites/default/files/resource-files/Good\%20Participatory\% 20Practice\%20guidelines_June_2011.pdf (accessed 2 Oct 2015). 